\title{
Chemical Characteristics of High PM Episodes Occurring in Spring 2014, Seoul, Korea
}

\author{
Hye Jung Shin, Seung-Myung Park, Jong Sung Park, In Ho Song, and You Deog Hong
}

Air Quality Research Division, National Institute of Environmental Research, Kyungseo-dong, Seo-gu, Incheon 404-708, Republic of Korea

Correspondence should be addressed to Hye Jung Shin; shjoung@korea.kr

Received 1 October 2015; Revised 24 December 2015; Accepted 12 January 2016

Academic Editor: Hang Xiao

Copyright @ 2016 Hye Jung Shin et al. This is an open access article distributed under the Creative Commons Attribution License, which permits unrestricted use, distribution, and reproduction in any medium, provided the original work is properly cited.

This study was conducted for understanding of characteristics of two different high PM episodes occurred during the spring of 2014 in Seoul, Korea. Case 1 was the phenomenon by complex of long range transport and following domestic stagnation. Case 2 was caused by the Asian dust event. During high PM episodes, atmospheric condition became more acidic. The equivalent concentration ratio of nitrate to sulfate decreased to 0.75 and 0.95 in Case 1 and Case 2, respectively, implying that sulfate concentration increase was greater than nitrate concentration increase in high PM episode possibly caused by long range transport. In high PM episodes, SOR and NOR increased with steeper rate for NOR. Considering correlation between temperature and SOR, it was suggested that the homogeneous formation of sulfate was not active in the Korean Peninsula, especially in high PM episodic periods. On the other hand, heterogeneous sulfate formation reaction was dominant for high PM episodes. Considering NOR and its correlation with temperature and humidity, it was suggested that $\mathrm{NO}_{2}$ oxidation was mainly caused by homogeneous oxidation in Case 1 . For Case 2 , heterogeneous oxidation mainly contributed to forming the nitrate due to the extremely high particle concentrations in Asian dust.

\section{Introduction}

Atmospheric particulate matter has been considered to play an important role in aggravating climate change and human health $[1,2]$. It is important to understand various atmospheric processes of aerosols and find out their emission sources for the establishment of pollution reduction policy to reduce adverse effects of aerosols on climate and public health. Moreover, understanding the chemical composition of atmospheric particles is necessary to identify their emission sources and predict their effects on various atmospheric processes [3].

Due to the fast economic growth of China, megacities such as Beijing have suffered from air pollution [4]. According to the recent studies, a large fraction of ambient particulate matter (PM) in Beijing is fine particles, which are mainly composed of organics, sulfate, nitrate, and ammonium [5-7]. The regional background concentrations of pollutants over the Asian continent are higher than those of other areas such as Europe and USA [8,9]. According to Tanimoto et al. [10], the most intensive influence of outflow from the Asian continent was centered at $30-40^{\circ} \mathrm{N}$, where the Korean Peninsula is located. The concentrations of air pollutants in the Korean Peninsula have been influenced by emissions in China and substantial transport of pollutants to the downwind area of China [11]. Ultimately, emitted air pollutants transport around the world and determine the global background concentrations [12]. Thus, understanding the chemical composition of PM especially for high PM episodes in Korea and predicting their emission source through this information are important to estimate the impacts of China, one of the world's largest emitters.

Although $\mathrm{PM}_{10}$ concentrations have slightly decreased in recent years in Korea [13], absolute concentration levels of $\mathrm{PM}_{10}$ are still higher than those in other advanced countries. In particular, high $\mathrm{PM}$ episodes, in which $\mathrm{PM}_{2.5}$ concentration of $50 \mu \mathrm{g} / \mathrm{m}^{3}$ or higher lasts over 6 hours, have increased in Korea (29 times, 2011; 58 times, 2012; 93 times, 2013). The contribution of high PM concentration to the total PM concentration has continuously increased in Seoul 


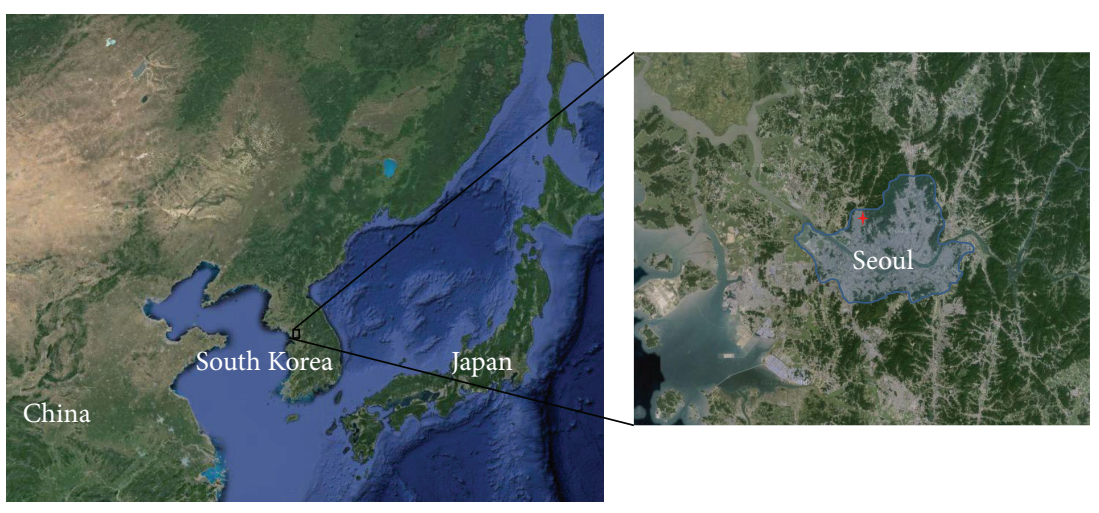

FIGURE 1: The location of monitoring site.

Metropolitan Area (SMA) consisting of Seoul, Incheon, and some parts of Gyeonggi Province surrounding Seoul and Incheon, Korea. Monthly averaged $\mathrm{PM}_{10}$ concentration in SMA in the last 11 years (2001 2011) was highest in March and lowest in August. Asian dust, which originated from Chinese desert areas and moved to the Korean Peninsula, and long range transport of air pollutants under the westerly wind condition have affected the particle concentrations in spring season [14].

The atmospheric pollution levels in SMA have been higher than those in any other region in Korea, indicating continuously increasing trends of secondary air pollutants $[13,15]$. In addition, the concentrations of $\mathrm{PM}_{10}$ in the SMA have not attained the national annual ambient air quality standard of Korea $\left(50 \mu \mathrm{g} / \mathrm{m}^{3}\right)$ [13]. Moreover, visibility, which is a proxy of ambient fine particles concentration, is lower in Seoul than in any other city in Korea [16]. The SMA is the largest region in Korea with almost half the population and about $45 \%$ of vehicles of Korea [17]. Therefore, studying the characteristics of atmospheric pollutants in SMA is important because of the representativeness of exposure to the public. In addition, the atmospheric pollutants of SMA originate from not only the domestic emission sources, but also the long range transport $[11,18]$. Thus, to characterize the atmospheric pollution in SMA is helpful to understand the complexity of air pollution and the effects of domestic and regional emissions.

In this study, the characteristics of different types of long lasting high PM episodes occurring in the end of February and March 2014 in SMA Intensive atmospheric Monitoring Station (SIMS) will be discussed to understand the high PM episodes. For this, we discussed the concentrations of chemical components, atmospheric acidity, and oxidation ability.

\section{Materials and Methods}

2.1. Monitoring Site and Methods. Korea Ministry of Environment (KMOE) has launched six intensive atmospheric monitoring sites in Baengnyeong Island, Seoul, Daejeon, Gwangju, Ulsan, and Jeju island to understand the long range transport of atmospheric pollutants and secure scientific data to support relevant policy for public health protection since
2009 [13]. In SIMS, which was launched in 2009, timeresolved chemical composition of $\mathrm{PM}_{2.5}$ has been measured on an hourly basis using Monitor for Aerosols and Gases in Ambient Air (MARGA, Metrohm Applikon) for ionic species, semicontinuous carbon monitor (SECOC Analyzer, Sunset) for carbonaceous components, and online X-ray fluorescence (XRF) (Xact 620, Cooper) for metals as well as mass concentrations of $\mathrm{PM}_{2.5}$ and $\mathrm{PM}_{10}$ (BAM1020, MetOne). The usual $\mathrm{PM}_{2.5}$ inlet systems of instrument for chemical composition monitoring were temporarily switched to the $\mathrm{PM}_{10}$ sampling inlet systems when Asian dust was forecasted by the Korea Meteorological Administration (KMA) except for carbonaceous measurement system. In this study, chemical composition data analyzed at SIMS in spring 2014 was used to understand the characteristics of different types of high PM episodes in SMA, Korea.

As shown in Figure 1, SIMS is located in northwest Seoul and adjacent to the Bukhansan National Park to the north and the suburban area to the northwest. To the south and southeast downtown of Seoul, residential areas and heavy traffic areas are located. Regionally, the Korean Peninsula is located in the northwesterly downwind direction of China in Northeast Asian region.

Meteorological data at the Regional Meteorological Observatory were obtained from the Korea Meteorological Administration (KMA) during the sampling period. Meteorological factors of interest were wind direction (WD), wind speed (WS), relative humidity $(\mathrm{RH})$, and atmospheric temperature $(T)$.

2.2. Instruments. $\mathrm{PM}_{10}$ and $\mathrm{PM}_{2.5}$ mass concentrations were continuously monitored by $\beta$-ray absorption method (BAM 1020, MetOne) with $16.7 \mathrm{~L} / \mathrm{min}$ equipped with $\mathrm{PM}_{10}$ impactor and $\mathrm{PM}_{2.5}$ Very Sharp Cut Cyclone (VSCC).

MARGA was used for ionic species monitoring. The air was put into the wet rotating denuder (WRD) via a $\mathrm{PM}_{2.5}$ inlet at flow rate of $16.7 \mathrm{~L} / \mathrm{min}$ to collect gaseous pollutants. After that, particulate matters were grown and collected in a steam jet aerosol collector (SJAC) with high temperature steam. Samples collected for one hour were separately injected to the cation and anion ion chromatography (Metrohm, Column Metrosep C 4 100/4.0; Column Metrosep A Supp. 10 
TABLE 1: Thermal program of EC/OC analysis.

\begin{tabular}{lccc}
\hline Program activity & Carrier gas & Time (seconds) & Program temperature \\
\hline Oven purge & Helium & 10 & Ambient \\
1st ramp & Helium & 60 & 250 \\
2nd ramp & Helium & 60 & 500 \\
3rd ramp & Helium & 60 & 650 \\
4th ramp & Helium & 90 & 850 \\
Cool for EC w/fan & Helium & 30 & - \\
Stabilize temperature & Helium & 45 & 550 \\
1st ramp & Helium/oxygen & 90 & 650 \\
2nd ramp & Helium/oxygen & 90 & 775 \\
3rd ramp & Helium/oxygen & 120 & 940 \\
External standard calibration and cool-down & Cal. gas + helium/oxygen & 120 & - \\
\hline
\end{tabular}

75/4.0) after mixing with $2.5 \mathrm{~mL}$ internal standard (lithium bromide). MARGA has an advantage to reduce errors caused due to variation of collection and injection volume by using internal standard. Details on the sampling program using the MARGA are in Metrohm Applikon [19]. For ion data, equivalent ratio and ion mass balance equation were considered to validate the data accuracy.

Atmospheric carbonaceous materials were monitored by SOCEC analyzer on an hourly basis with modified NIOSH method 5040 [20] as shown in Table 1. The instruments are equipped with $\mathrm{PM}_{2.5}$ cyclone for the sampler inlet and organic denuders for removing gaseous organic carbons [21]. Samples were collected for 45 minutes at $8 \mathrm{~L} / \mathrm{min}$ flow rate on the $47 \mathrm{~mm}$ quartz filters (Tissuquartz, Gelman Sciences). After the sample collection, the oven was purged with helium and heated to $850^{\circ} \mathrm{C}$ by a stepped temperature ramp, in which thermally desorbed organic compounds and pyrolysis products were put into a manganese dioxide $\left(\mathrm{MnO}_{2}\right)$ oxidizing oven. The carbon fragments, converted to $\mathrm{CO}_{2}$ gas in $\mathrm{MnO}_{2}$ oven, were measured directly by a self-contained nondispersive infrared (NDIR) detector system. A second temperature ramp was then initiated in oxidizing gas stream and any elemental carbon was oxidized off the filter and put into the oxidizing oven. The elemental carbon was then detected in the same manner as the organic carbon.

The elements such as $\mathrm{Si}, \mathrm{S}, \mathrm{K}, \mathrm{Ca}, \mathrm{Ti}, \mathrm{V}, \mathrm{Cr}, \mathrm{Mn}, \mathrm{Fe}$, $\mathrm{Co}, \mathrm{Ni}, \mathrm{Cu}, \mathrm{Zn}, \mathrm{Ga}, \mathrm{As}, \mathrm{Se}, \mathrm{Br}, \mathrm{Mo}, \mathrm{Cd}, \mathrm{Sb}, \mathrm{Ba}, \mathrm{Hg}, \mathrm{Ta}$, and $\mathrm{Pb}$ were monitored using online XRF. This instrument is based on reel to reel (RTR) filter tape sampling followed by nondestructive XRF analysis of metals. It consists of a $\mathrm{PM}_{2.5}$ inlet, a temperature sensor, a sampling module, an analysis module, and a flow control module. The instruments equipped with $\mathrm{PM}_{2.5}$ cyclone for the sampler inlet and samples were collected for 60 minutes at $16.7 \mathrm{~L} / \mathrm{min}$ flow rate. Among 24 elements, only 7 elements (potassium, calcium, iron, nickel, arsenic, selenium, and lead) data were used due to significance of the concentration level and quality assurance issue considering the comparison with filter based ICP-MS (Inductively Coupled Plasma-Mass Spectrometry) analysis results (only internal documents).

\section{Results}

3.1. Characteristics of Chemical Composition in Two Cases. Time series of $\mathrm{PM}_{10}$ and $\mathrm{PM}_{2.5}$ mass concentrations and major chemical components such as inorganics (sulfate, nitrate, ammonium, and calcium), carbonaceous components (organic carbon and elemental carbon), and elements (potassium, calcium, iron, nickel, arsenic, selenium, and lead) with $\mathrm{PM}_{2.5}$ and $\mathrm{PM}_{10}$ inlet are shown in Figure 2. The statistics of major components are shown in Table 2. As shown in Figure 2, there were apparently two high peaks in all components: one on February 21, 2014 (Case 1), and the other on March 18, 2014 (Case 2). The eidetic difference between Case 1 and Case 2 was the $\mathrm{PM}_{2.5}$ to $\mathrm{PM}_{10}$ ratio. Compared to the annual averaged $\mathrm{PM}_{2.5} / \mathrm{PM}_{10}$ ratio $(0.63)$, those of Case 1 and Case 2 were extremely high and low, respectively. Detailed characteristics are discussed later on. During the period of Case 2, the inlet system was changed from $\mathrm{PM}_{2.5}$ (period (a) in Figure 2) to $\mathrm{PM}_{10}$ (period (b) in Figure 2) due to the forecasting of Asian dust, which was recognized by Korean Meteorological Administration. The inlet system reswitched from $\mathrm{PM}_{10}$ (period (b) in Figure 2) to $\mathrm{PM}_{2.5}$ (period (a) in Figure 2) after ending of Asian dust event. Note that the chemical components in Case 2 were bounded to $\mathrm{PM}_{10}$. As shown in Table 2, the annual average concentrations of $\mathrm{PM}_{10}$ and $\mathrm{PM}_{2.5}$ of this site were $59 \mu \mathrm{g} / \mathrm{m}^{3}$ and $37 \mu \mathrm{g} / \mathrm{m}^{3}$, respectively. And the annual averaged $\mathrm{PM}_{2.5}$ to $\mathrm{PM}_{10}$ ratio was 0.63. In Case $1, \mathrm{PM}_{10}$ and $\mathrm{PM}_{2.5}$ concentrations increased to $142 \mu \mathrm{g} / \mathrm{m}^{3}$ and $112 \mu \mathrm{g} / \mathrm{m}^{3}$, respectively, with high $\mathrm{PM}_{2.5}$ to $\mathrm{PM}_{10}$ ratio of 0.79 . On the other hand, $\mathrm{PM}_{10}$ concentration increased to $165 \mu \mathrm{g} / \mathrm{m}^{3}$ in Case 2 with relatively low $\mathrm{PM}_{2.5}$ concentration of $66 \mu \mathrm{g} / \mathrm{m}^{3}$ and low $\mathrm{PM}_{2.5}$ to $\mathrm{PM}_{10}$ ratio of 0.4. More details on the two cases are as follows.

In Case $1, \mathrm{PM}_{10}$ concentrations in SMA started to increase to over $100 \mu \mathrm{g} / \mathrm{m}^{3}$, which is the daily averaged national air quality standard in Korea, from 21 LST, 21 February, 2014, and lasted as long as 186 hrs. $\mathrm{PM}_{10}$ and $\mathrm{PM}_{2.5}$ concentrations were 2.4 times and 3.0 times higher than those measured for the whole year, respectively. In particular, sulfate concentration increase was apparent, 3.6 times higher 

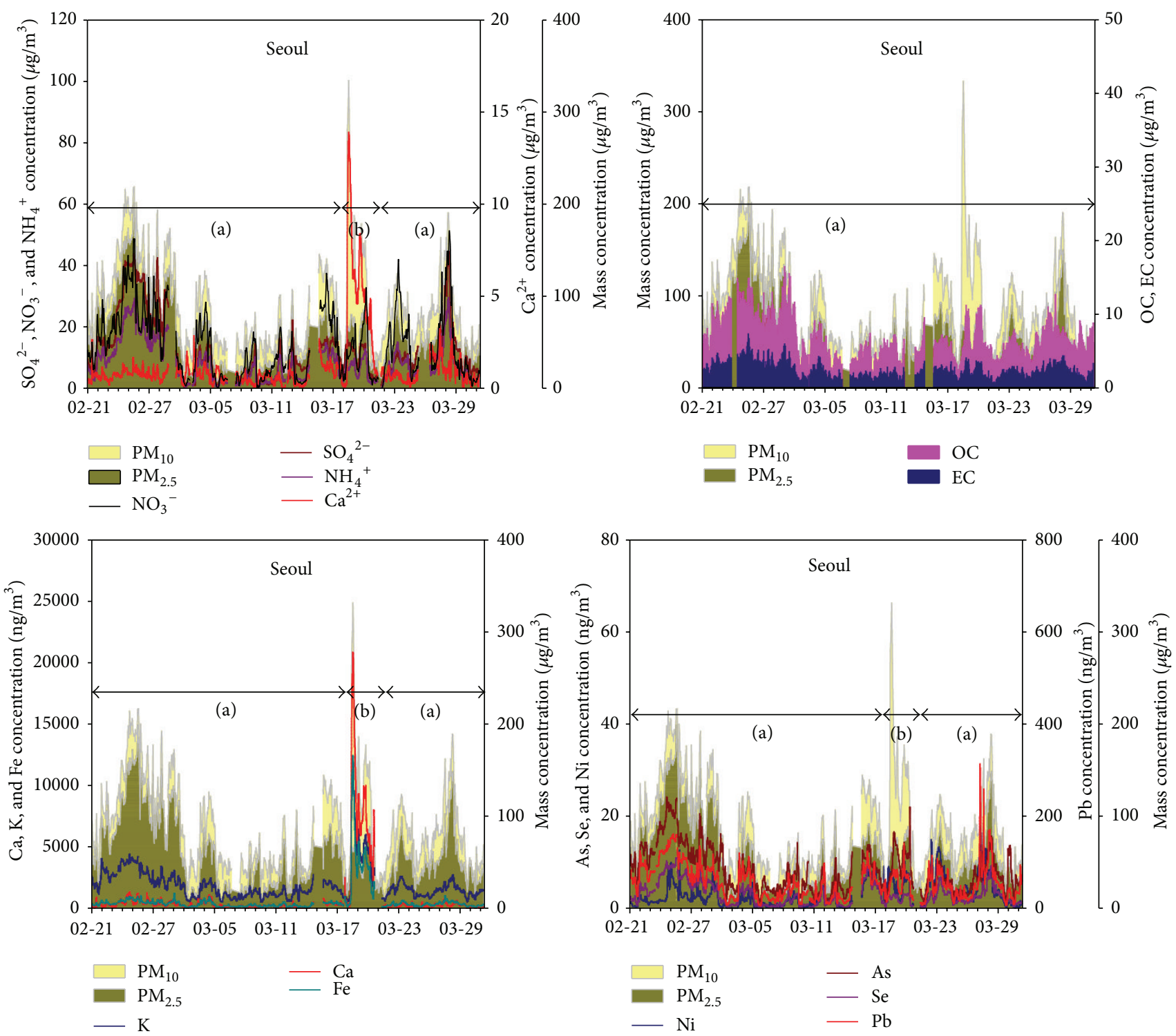

FIGURE 2: The time series of individual chemical components of episodic periods bounded: (a) $\mathrm{PM}_{2.5}$ and (b) $\mathrm{PM}_{10}$.

than the annual average concentration. Trace elements such as arsenic, selenium, and lead also increased to 3.0 3.2 times higher than the average concentrations (Table 2). On the other hand, the concentration of crustal elements such as calcium and iron slightly increased to 1.7 2.5 times, which was relatively low. Elemental and organic carbon concentrations also increased to 2.8 and 2.3 times higher than the annual average. As a result of backward trajectory, the air parcel was moved to the Korean Peninsula through the northeastern part of China, where megacities such as Beijing, Hebei, and Tianjin are located, in the beginning of Case 1 (Figure 3). However, in the latter part of Case 1 episode, air parcel was stagnated over the Korean Peninsula. It was thought that Case 1 episode was affected not only by the long range transport of atmospheric pollutants but also by the domestic stagnation.

In Case 2, high PM episode lasted only for 48 hours with a low $\mathrm{PM}_{2.5} / \mathrm{PM}_{10}$ ratio (0.4). Even though the $\mathrm{PM}_{10}$ concentration was 1.2 times higher than that of Case $1, \mathrm{PM}_{2.5}$ concentration $\left(66 \mu \mathrm{g} / \mathrm{m}^{3}\right)$ was much lower in this period (0.59 times). In addition, calcium ion concentration sharply increased to $7.0 \mu \mathrm{g} / \mathrm{m}^{3}$ and elemental calcium concentration also increased to $9.0 \mu \mathrm{g} / \mathrm{m}^{3}$, which were higher than those of annual average, even considering the inlet difference. Otherwise, carbonaceous concentration slightly increased. In this period, the air parcel came from the Inner Mongolian and Gobi Desert area, one of the major sources of Asian dust. Case 2 episode showed the characteristics of typical Asian dust event in chemical composition. According to the Chinese atmospheric monitoring data from CEMC [22], which reports data on atmospheric pollutant concentrations for the last 24 hours, $\mathrm{PM}_{10}$ concentration in Beijing, China, increased to over $100 \mu \mathrm{g} / \mathrm{m}^{3}$ from March 13, 2014, to the night of March 17, 2014, with lower $\mathrm{PM}_{2.5} / \mathrm{PM}_{10}$ ratio of 0.4 (Figure 4). $\mathrm{PM}_{10}$ concentration measured in Tianjin and 
TABLE 2: Chemical composition of Case 1 and Case 2 compared to annual average.

\begin{tabular}{|c|c|c|c|c|}
\hline \multicolumn{2}{|c|}{ Species } & Annual average & Case 1 & Case 2 \\
\hline \multirow{2}{*}{ Mass } & $\mathrm{PM}_{10}$ & $59 \pm 40^{(1)}$ & $142 \pm 35(2.4)^{(2)}$ & $165 \pm 58(2.8)$ \\
\hline & $\mathrm{PM}_{2.5}$ & $37 \pm 28$ & $112 \pm 30(3.0)$ & $66 \pm 16(1.8)$ \\
\hline \multirow{2}{*}{ Carbons } & Organic carbon & $3.8 \pm 2.7$ & $10.5 \pm 2.0(2.8)$ & $7.9 \pm 2.3(2.1)$ \\
\hline & Elemental carbon & $1.6 \pm 1.0$ & $3.7 \pm 0.9(2.3)$ & $2.5 \pm 0.8(1.6)$ \\
\hline \multirow{8}{*}{ Ions } & Sulfate & $7.5 \pm 8.3$ & $26.7 \pm 9.9(3.6)$ & $12.4 \pm 2.5$ \\
\hline & Nitrate & $8.0 \pm 8.2$ & $24.5 \pm 8.7(3.1)$ & $15.4 \pm 6.8$ \\
\hline & Chloride & $0.5 \pm 0.7$ & $1.0 \pm 0.7(2.0)$ & $1.4 \pm 0.9$ \\
\hline & Sodium & $0.2 \pm 0.2$ & $0.2 \pm 0.1(1.0)$ & $0.8 \pm 0.4$ \\
\hline & Ammonium & $5.0 \pm 5.0$ & $16.6 \pm 5.5(3.3)$ & $7.7 \pm 2.5$ \\
\hline & Potassium & $0.2 \pm 0.2$ & $0.6 \pm 0.2(2.5)$ & $0.5 \pm 0.2$ \\
\hline & Magnesium & $0.2 \pm 0.3$ & $0.4 \pm 0.3(2.0)$ & $1.1 \pm 0.4$ \\
\hline & Calcium & $0.5 \pm 1.0$ & $0.8 \pm 0.3(1.6)$ & $7.0 \pm 2.9$ \\
\hline \multicolumn{5}{|c|}{ Sum of ionic species } \\
\hline \multirow{7}{*}{ Metals } & Calcium & $0.2 \pm 0.3$ & $0.5 \pm 0.3(2.5)$ & $9.0 \pm 4.3$ \\
\hline & Potassium & $1.0 \pm 0.7$ & $2.9 \pm 0.7(2.9)$ & $5.8 \pm 2.1$ \\
\hline & Iron & $0.3 \pm 0.2$ & $0.5 \pm 0.2(1.7)$ & $4.8 \pm 2.6$ \\
\hline & Nickel & $0.002 \pm 0.003$ & $0.003 \pm 0.002(1.5)$ & $0.005 \pm 0.002$ \\
\hline & Arsenic & $0.005 \pm 0.004$ & $0.015 \pm 0.004(3.0)$ & $0.012 \pm 0.003$ \\
\hline & Selenium & $0.002 \pm 0.002$ & $0.006 \pm 0.002(3.0)$ & $0.002 \pm 0.001$ \\
\hline & Lead & $0.030 \pm 0.031$ & $0.097 \pm 0.029$ & $0.066 \pm 0.020$ \\
\hline
\end{tabular}

${ }^{(1)}$ Each value is the average \pm standard deviation.

${ }^{(2)}$ The values in parenthesis are the ratio of each parameter compared to the annual average concentration.

Hebei, metropolitan areas of China adjacent to Beijing, also increased to over $100 \mu \mathrm{g} / \mathrm{m}^{3}$ and reached maximum concentration of $688 \mu \mathrm{g} / \mathrm{m}^{3}$ during the same period. It was thought that the Asian dust occurring in the Inner Mongolian and Gobi Desert area passed through the Northeast area of China including Beijing and reached the Korean Peninsula showing particulate concentration gradient. The maximum concentration of $\mathrm{PM}_{10}$ in Seoul was $333 \mu \mathrm{g} / \mathrm{m}^{3}$ during this period.

The calcium, sulfate, and elemental carbon (EC) concentrations, the major components representing the different characteristics of each case, were shown in Figure 5. Calcium is the tracer component representing the characteristics of crustal or soil source. Otherwise, EC and sulfate are the major components tracing the long range transport of air parcel from urban China due to the huge amount of emission in China region. For Case 1, the concentrations of EC and sulfate were much higher than calcium concentration showing similar variation with the $\mathrm{PM}_{2.5}$ mass concentration. Otherwise, calcium ion concentration was much higher than EC concentration in Case 2. And the variation of calcium ion concentration was similar to $\mathrm{PM}_{10}$ mass concentration change.

3.2. Aerosol Acidity and Oxidation Ratios for Sulfate and Nitrate. Acidity of particles is affecting the aerosol growth, toxic characteristics, and chemical reactions in atmosphere. Thus, possibility of acidity changes in high PM episodes was considered to estimate of high PM episodic effects. The acidity of particle was examined by comparing the measured ammonium concentration to ammonium amount required to fully neutralize the atmospheric anions (hereafter, predicted ammonium)

$$
\begin{aligned}
\mathrm{NH}_{4}{ }_{\text {predict }}^{+}= & 18 \\
& \times\left(2 \times \frac{\left[\mathrm{SO}_{4}{ }^{2-}\right]}{96}+\frac{\left[\mathrm{NO}_{3}{ }^{-}\right]}{62}+\frac{\left[\mathrm{Cl}^{-}\right]}{35.5}\right)
\end{aligned}
$$

In the equation, $\left[\mathrm{SO}_{4}{ }^{2-}\right],\left[\mathrm{NO}_{3}{ }^{-}\right]$, and $\left[\mathrm{Cl}^{-}\right]$are the mass concentrations of each pollutant. 18, 96, 62, and 35.5 are the molecular weights of ammonium, sulfate, nitrate, and chloride, respectively.

The scatter plots of measured and predicted ammonium concentrations for Case 1, Case 2, and the whole year are shown in Figure 6. Annually, measured ammonium concentrations are relatively lower than predicted ammonium concentrations, implying that the atmospheric condition is relatively acidic. For Case 1, atmospheric condition changed to be more acidic, decreasing the slope from 0.941 to 0.937 . Sulfate and nitrate concentrations in Case 1 were much higher than those for the whole year; even sulfate concentration increase was more apparent. It was thought that the increasing of major anions caused changes in aerosol acidity. For Case 2, which is a typical Asian dust case, the slope was 0.871, much lower than Case 1. According to He et al. [23], mineral dust can affect aerosol acidity by either neutralizing the acidic aerosol (positive effect) or increasing the surface area of heterogeneous reaction for the acids (negative effect). Several indicators showing the acidic condition of atmosphere were 


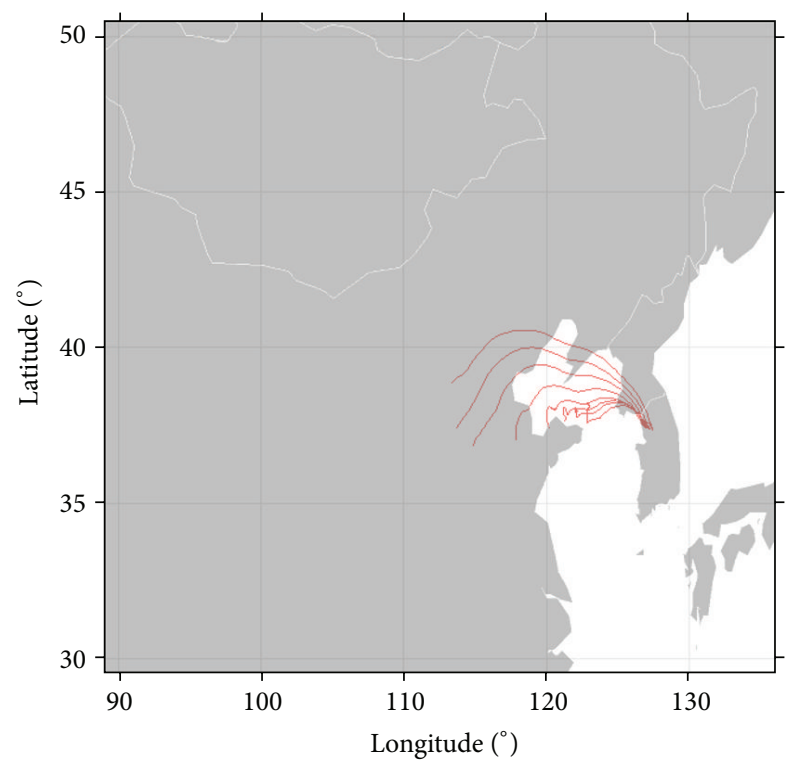

(a)

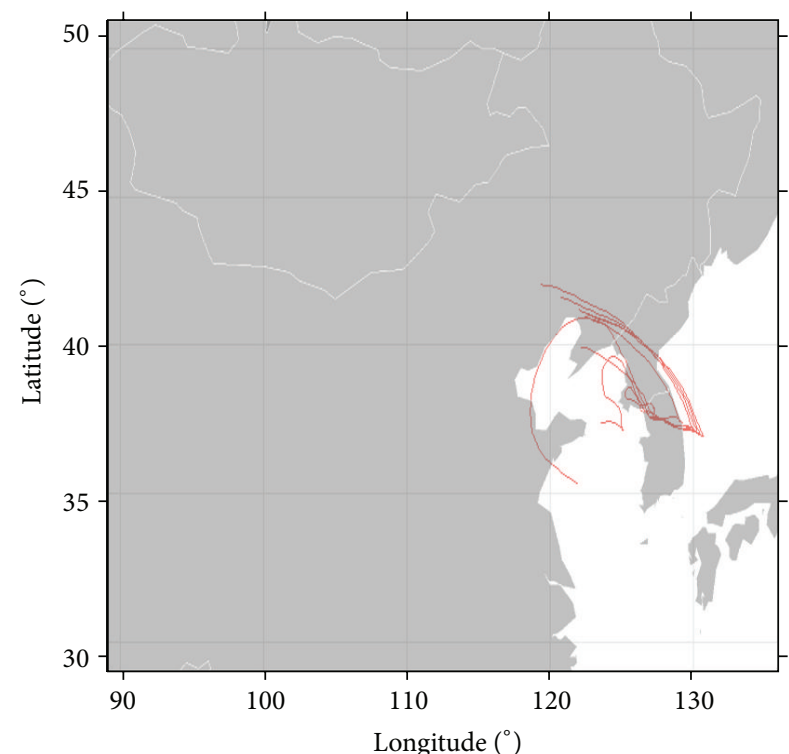

(b)

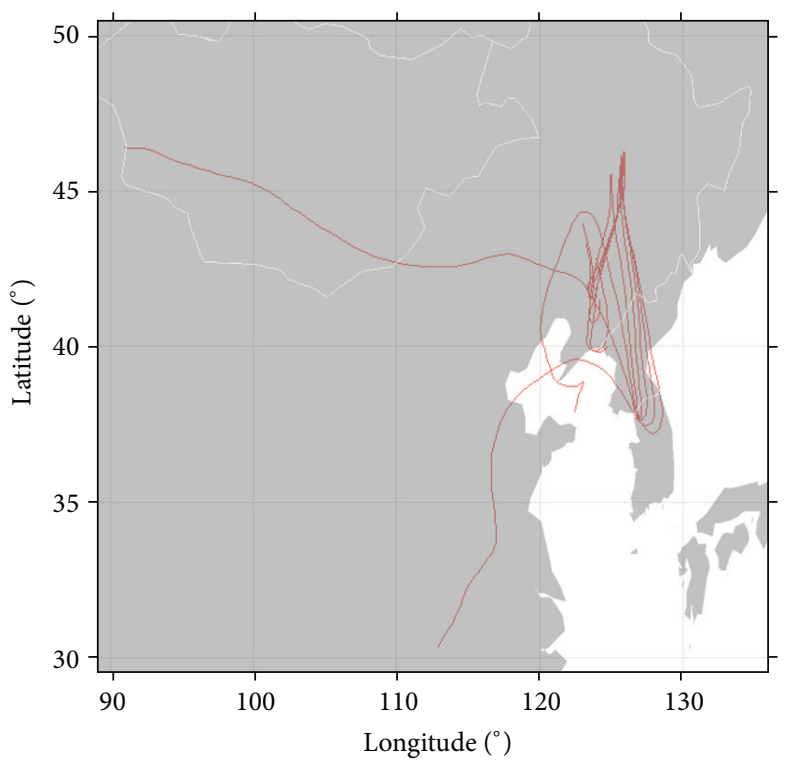

(c)

FIgURE 3: Backward trajectory (a) in the former period of Case 1, (b) in the latter period of Case 1, and (c) in Case 2.

shown in Table 3. The equivalent concentration ratios of nitrate to sulfate were 0.75 and 0.95 in Case 1 and Case 2, respectively. They are much lower than the average of the whole year (1.28), which implies that sulfate concentration increase is greater than nitrate concentration increase in high PM episode possibly caused by long range transport. The relative concentration of nitrate to sulfate in Case 2 was higher than that in Case 1 (Figure 7). It was possible that the Asian dust particles provided enough surfaces for heterogeneous reactions for the nitrate as mentioned before. Throughout the several previous studies, it was revealed that the reactions with alkaline mineral components are much faster for gaseous $\mathrm{HNO}_{3}$ than for $\mathrm{NO}_{2}$ and $\mathrm{SO}_{2}[24,25]$.
Figure 8 shows the correlation of ammonium versus sulfate and ammonium versus sulfate + nitrate equivalent concentration for each case. According to previous studies conducted in China [26, 27], ammonia in the aerosols could be neutralized first by $\mathrm{H}_{2} \mathrm{SO}_{4}$ to form $\left(\mathrm{NH}_{4}\right)_{2} \mathrm{SO}_{4}$ or $\mathrm{NH}_{4} \mathrm{HSO}_{4}$, and then remaining parts could be neutralized by reactions with $\mathrm{HNO}_{3}$ to form $\mathrm{NH}_{4} \mathrm{NO}_{3}$. The correlations between ammonium and sulfate (Figure 8(a)) were relatively weaker in Case 2 and strong in Case 1 with higher correlation coefficient $\left(R^{2}=0.90\right)$. In addition, correlations between ammonium and sulfate + nitrate (Figure $8(b)$ ) were very strong, and sulfate + nitrate was fully neutralized by ammonia in Case 1 and Case 2. Considering the result shown in 


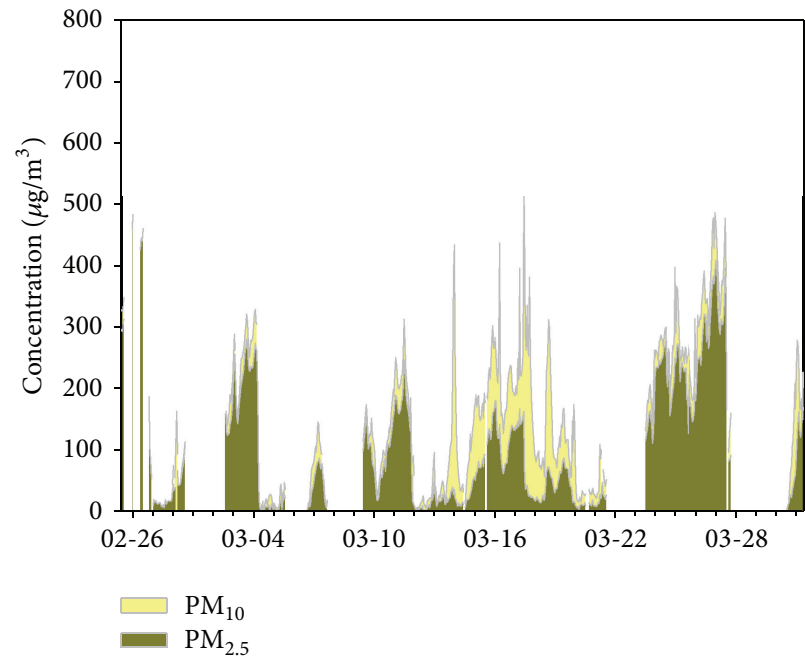

(a)

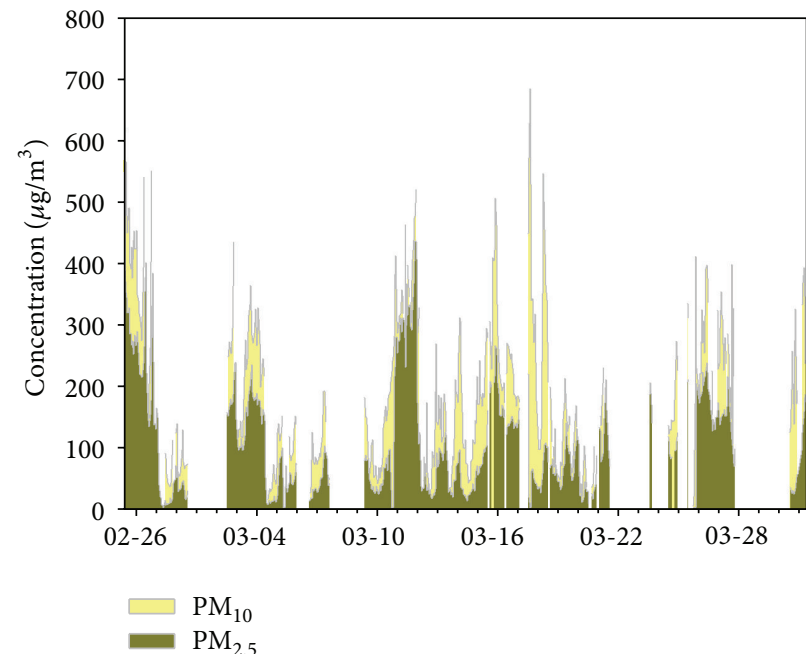

(b)

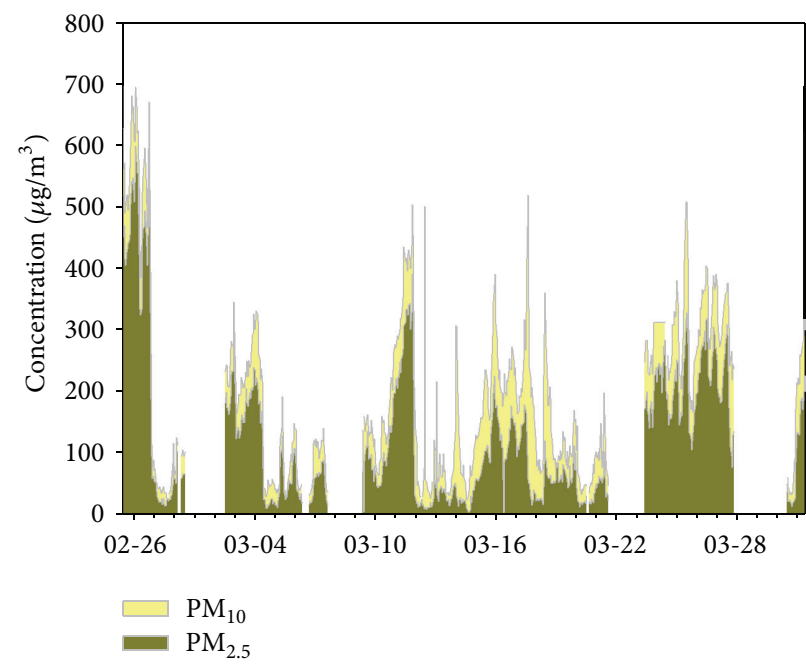

(c)

Figure 4: Mass concentration of major cities in China. (a) Beijing, (b) Tianjin, and (c) Hebei.

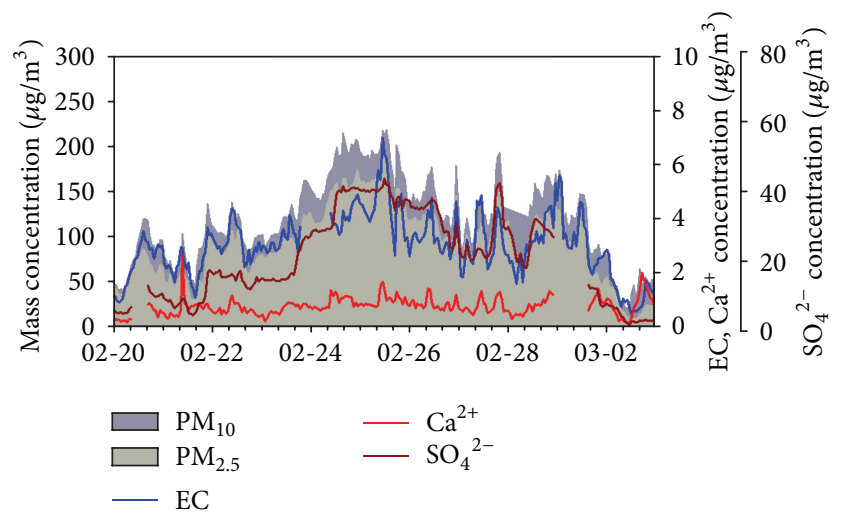

(a)

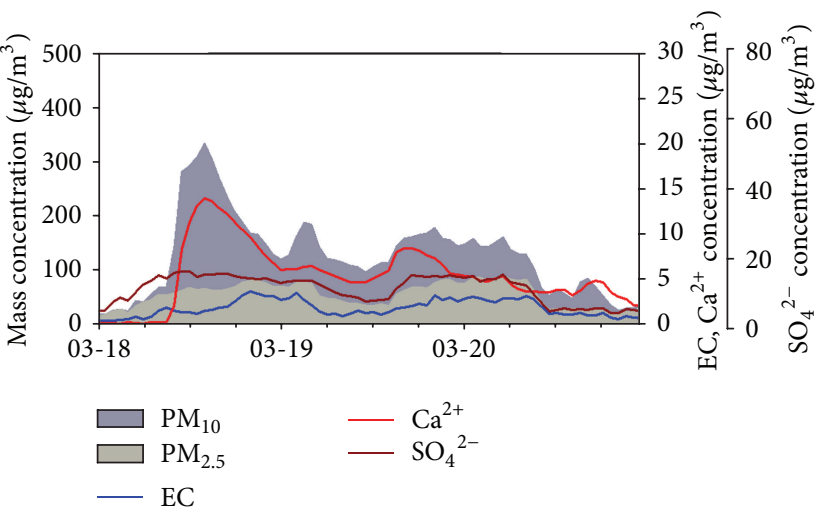

(b)

Figure 5: Time series of ionic calcium, elemental carbon, and sulfate concentration in (a) Case 1 and (b) Case 2. 
TABLE 3: Several indicators for acidic condition and oxidation state of atmosphere.

\begin{tabular}{|c|c|c|c|}
\hline Chemicals & Annual average & Case 1 & Case 2 \\
\hline $\mathrm{NO}_{3}{ }^{-}$-eq $/ \mathrm{SO}_{4}{ }^{2-}$ _eq & 1.28 & 0.75 & 0.95 \\
\hline $\mathrm{Ca}^{2+} \_$eq $/ \mathrm{NH}_{4}^{+}{ }^{+}$eq & 0.19 & 0.04 & 0.92 \\
\hline SOR & 0.22 & 0.39 & 0.34 \\
\hline NOR & 0.08 & 0.15 & 0.13 \\
\hline$R^{2}$ (SOR temperature) & 0.075 & 0.027 & 0.003 \\
\hline$R^{2}$ (NOR temperature) & 0.001 & 0.040 & 0.083 \\
\hline$R^{2}(\mathrm{SOR}-\mathrm{RH})$ & 0.027 & 0.380 & 0.107 \\
\hline$R^{2}(\mathrm{NOR}-\mathrm{RH})$ & 0.028 & 0.003 & 0.218 \\
\hline
\end{tabular}

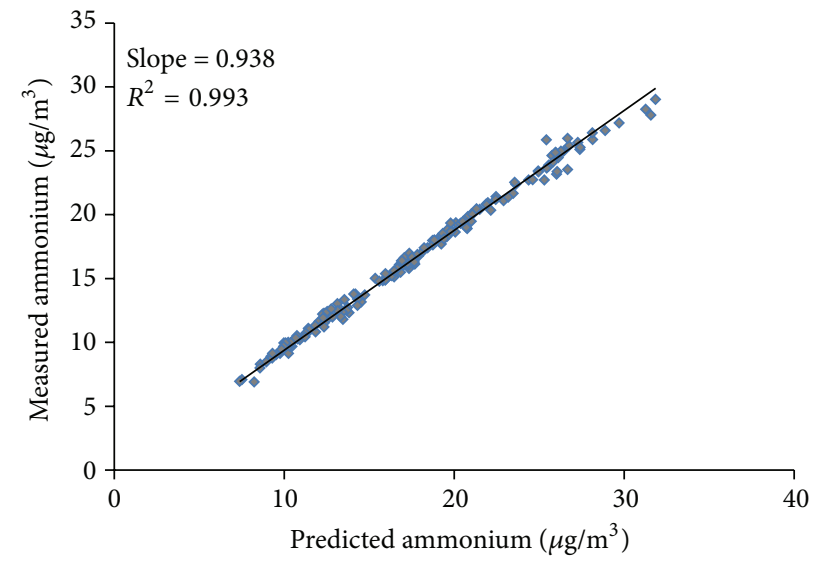

(a)

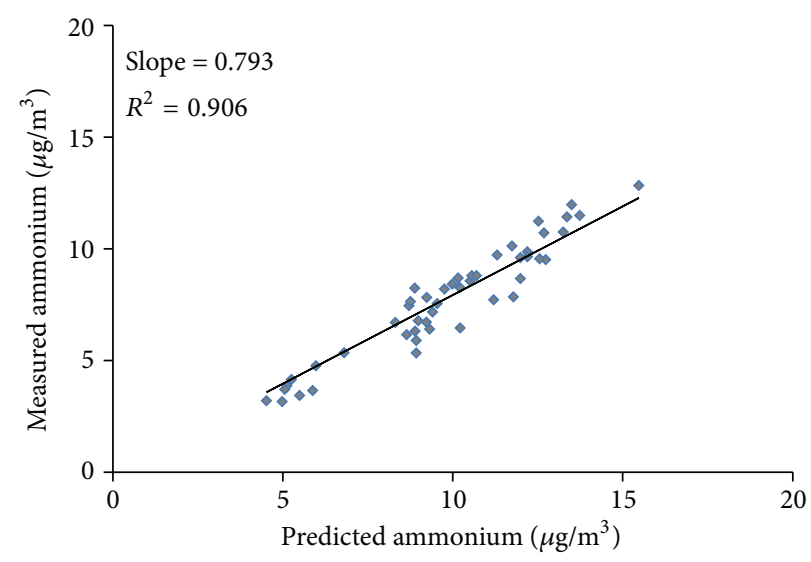

(b)

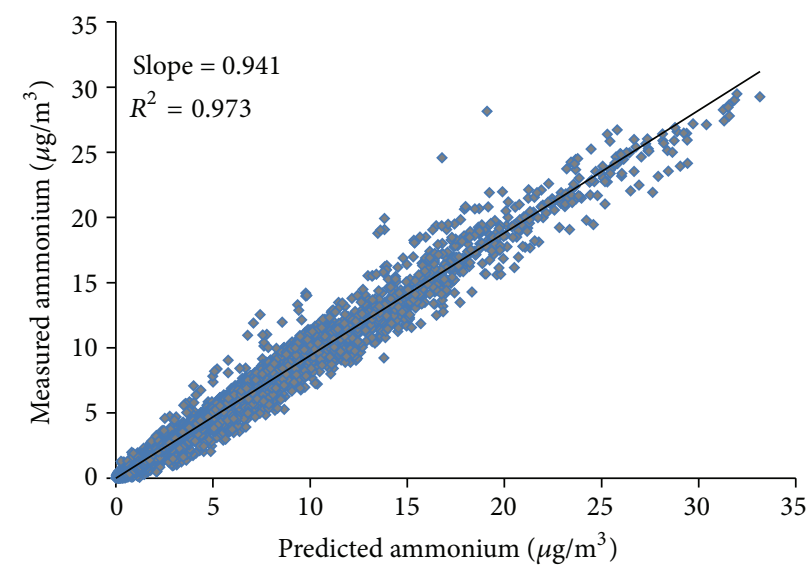

(c)

FIGURE 6: Correlation between measured ammonium and predicted ammonium. (a) Case 1, (b) Case 2, and (c) annual total.

Figure 8, ammonium concentration is just enough to neutralize sulfate and nitrate. However, the presence of other anions makes the atmosphere a bit acidic. The slope increasing for sulfate + nitrate correlation compared to sulfate correlation in Case 2 was much steeper from 0.239 to 1.002 . It was thought that the contribution of nitrate was much higher in Case 2. It is coincident that the Asian dust particles contribute to fast formation of nitrate on their surface.

Sulfur oxidation ratio (SOR) and nitrogen oxidation ratio (NOR) were also considered as well as equivalent ratios of ionic species to evaluate the degree of atmospheric conversion of $\mathrm{SO}_{2}$ and $\mathrm{NO}_{2}$ to sulfate and nitrate, respectively. SOR and NOR were calculated using the following equations [28]:

$$
\begin{aligned}
\mathrm{SOR} & =\frac{\left[\mathrm{SO}_{4}{ }^{2-}\right]}{\left\{\left[\mathrm{SO}_{4}{ }^{2-}\right]+\left[\mathrm{SO}_{2}\right]\right\}} \\
\mathrm{NOR} & =\frac{\left[\mathrm{NO}_{3}{ }^{-}\right]}{\left\{\left[\mathrm{NO}_{3}{ }^{-}\right]+\left[\mathrm{NO}_{2}\right]\right\}}
\end{aligned}
$$




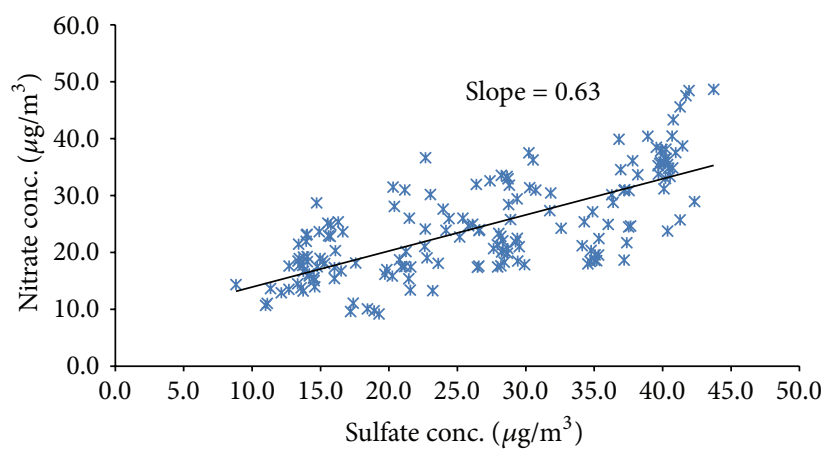

(a)

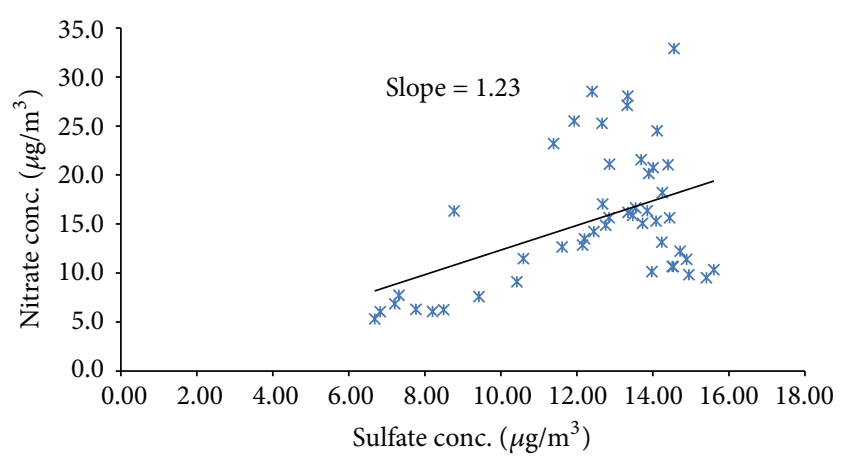

(b)

Figure 7: Correlation between sulfate and nitration concentration of (a) Case 1 and (b) Case 2.

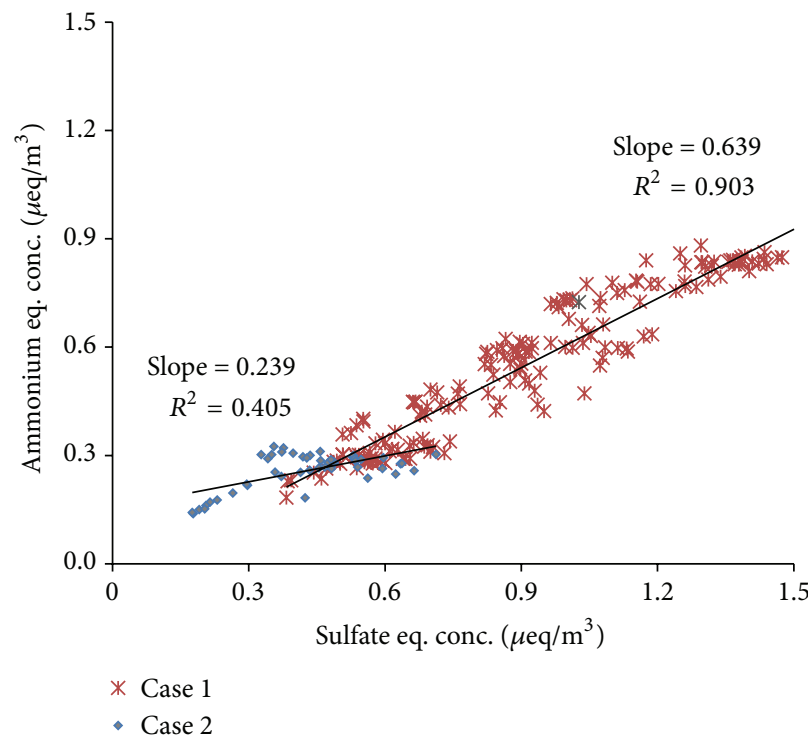

(a)

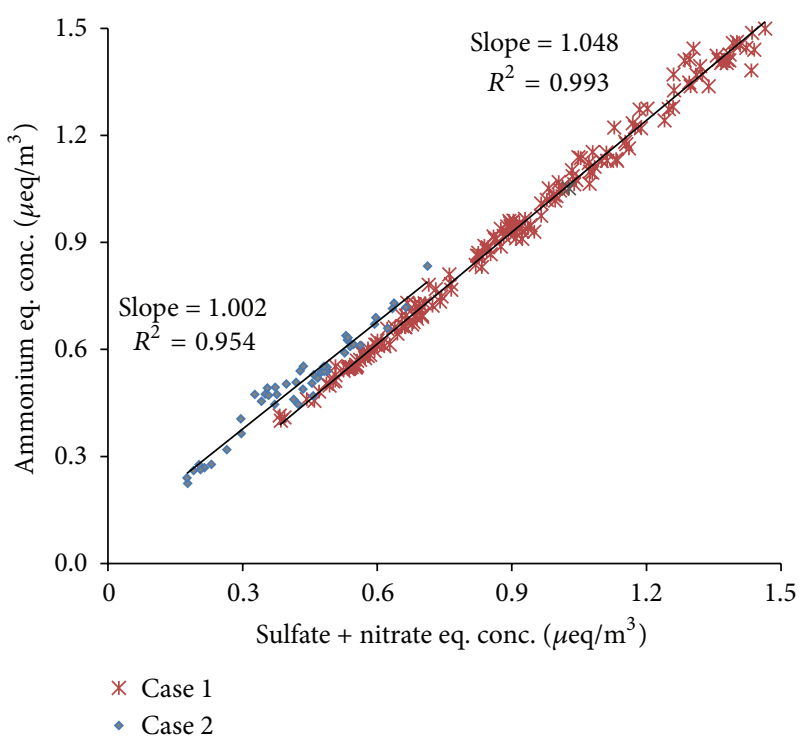

(b)

FIGURE 8: Correlation between equivalent concentration of ammonium and equivalent concentration of (a) sulfate and (b) sulfate + nitration in Case 1 and Case 2.

In the equation, $\left[\mathrm{SO}_{4}{ }^{2-}\right],\left[\mathrm{NO}_{3}{ }^{-}\right],\left[\mathrm{SO}_{2}\right]$, and $\left[\mathrm{NO}_{2}\right]$ are molar concentrations of each chemical species. Generally, nss$\mathrm{SO}_{4}{ }^{2-}$ concentration, which is calculated as $\mathrm{SO}_{4}{ }^{2-}-0.2514 \times$ $\mathrm{Na}^{+}$, is used in SOR. However, sodium concentration is generally 2 of order lower than sulfate concentration, and contribution of ss- $\mathrm{SO}_{4}{ }^{2-}$ is negligible. Thus, total sulfate concentration is used in this study.

SOR in Case 1 was 0.39, which is lower than the measurements in previous studies in India (haze and fog event; 0.45 0.52) and a little higher than in China (haze event; $0.15 \sim 0.29)$. SOR in Case 2 was relatively lower than Case 1 (0.34). NORs in Case 1 and Case 2 were 0.15 and 0.13 , respectively. These are lower than those in India (haze and fog event; $0.20 \sim 0.39$ ) and China (haze event; 0.15 0.29). The oxidation efficiencies of $\mathrm{SO}_{2}$ to $\mathrm{SO}_{4}{ }^{2-}$ and $\mathrm{NO}_{2}$ to $\mathrm{NO}_{3}{ }^{-}$ are generally lower than those in China and India. However, compared to the annual averaged SOR (0.22) and NOR (0.08), oxidation efficiency in episodic period increased from
1.6 times to 2.0 times higher ratio with steeper increasing for NOR as shown in Table 3. Even though the SOR value increased in episodic cases, correlation between temperature and SOR was generally low $\left(R^{2}=0.075\right)$ and even decreased to $0.003 \sim 0.027$ in episodic cases. Homogeneous oxidation processes, the gas-phase reaction of $\mathrm{SO}_{2}$ with $\mathrm{OH}$ radicals, are temperature dependent process. Thus, it was suggested that the homogeneous formation of sulfate was not active in the Korean Peninsula, especially in high PM episodic periods. Heterogeneous oxidation reaction can take place on dust aerosol surfaces, aqueous transformation, and incloud scavenging processes. Moreover, long range transport of preformed sulfate would be considered. The heterogeneous processes such as aqueous transformation and incloud scavenging processes are positively correlated with relative humidity. As shown in Table 3, correlation between humidity and SOR increased from 0.028 to 0.38 and 0.107 in Case 1 and Case 2, respectively. It was concluded that 
the heterogeneous sulfate formation reaction was dominant in high PM episodes.

As for NOR, correlations with temperature and relative humidity were calculated as shown in Table 3. As for NOR, correlation with temperature highly increased from 0.001 to 0.040 and 0.083 for Case 1 and Case 2, respectively, in contrast to SOR. Considering the fact that the homogeneous oxidation is temperature dependent, it was assumed that $\mathrm{NO}_{2}$ oxidation by homogeneous oxidation tends to increase in high PM episode, especially for Case 2. However, the NOR correlation with humidity decreased in Case 1 and highly increased in Case 2. Considering the preferred reaction of heterogeneous process under high relative humidity, it was assumed that heterogeneous oxidation increased in Case 2. Thus, it was suggested that $\mathrm{NO}_{2}$ oxidation was mainly caused by homogeneous oxidation in Case 1 considering the increase of correlation with temperature and decrease of correlation with relative humidity. On the other hand, it was assumed that the heterogeneous oxidation mainly contributed to form the nitrate for Case 2 as well as homogeneous oxidation considering the concurrent increase of correlation with temperature and relative humidity due to the extremely high particle concentrations in Asian dust.

\section{Summary and Conclusions}

In order to understand the characteristics of high PM episodes, the chemical components of $\mathrm{PM}_{2.5}$ were monitored and aerosol acidity and oxidation ratios were analyzed in spring 2014. During this period, apparent two high PM episodes occurred: (a) Case 1, (b) Case 2. For Case 1, $\mathrm{PM}_{2.5}$ to $\mathrm{PM}_{10}$ ratio was 0.79 with $\mathrm{PM}_{10}$ and $\mathrm{PM}_{2.5}$ mass concentrations of $142 \mu \mathrm{g} / \mathrm{m}^{3}$ and $112 \mu \mathrm{g} / \mathrm{m}^{3}$, respectively. Sulfate and trace elements such as arsenic, selenium, and lead concentrations apparently increased in this case, implying that the anthropogenic source mainly affected the atmospheric condition. According to the backward trajectory, this case could be divided into two subepisodes. In the former period, air parcel was moved to the Korean Peninsula through the northeastern part of China. However, in the latter period of Case 1 episode, air parcel was stagnated over the Korean Peninsula. As a result, Case 1 has occurred resulting from the combination of long range transport and domestic stagnation of air parcel.

In Case 2, $\mathrm{PM}_{2.5} / \mathrm{PM}_{10}$ ratio was relatively low (0.4). In addition, calcium ion concentration sharply increased to $7.0 \mu \mathrm{g} / \mathrm{m}^{3}$ and elemental calcium concentration also increased to $9.0 \mu \mathrm{g} / \mathrm{m}^{3}$. According to the air parcel movement, it was thought that the Asian dust occurring in the Inner Mongolian and Gobi Desert area passed through the Northeast area of China including Beijing and reached the Korean Peninsula showing particulate concentration gradient.

During high PM episodes, atmospheric condition became more acidic, decreasing the slope between measured ammonium and predicted ammonium from 0.941 to 0.937 and 0.871 in Case 1 and Case 2, respectively. It was thought that the increasing of major anions and the surface area for heterogeneous reaction caused changes in aerosol acidity.
The equivalent concentration ratios of nitrate to sulfate decreased to 0.75 and 0.95 in Case 1 and Case 2, respectively, implying that sulfate concentration increase is greater than nitrate concentration increase in high PM episode possibly caused by long range transport. However, relative concentration of nitrate to sulfate for Case 2 was higher than Case 1. It was possible that the Asian dust particles provide enough surfaces for heterogeneous reaction for the nitrate. Steeper increase of correlation between ammonium and sulfate + nitrate rather than between ammonium and sulfate for Case 2 also suggested that the contribution of nitrate was much higher than Case 1, possibly due to the Asian dust particles. In high PM episodes, oxidation ratio of $\mathrm{SO}_{2}$ (SOR) and $\mathrm{NO}_{2}$ (NOR) increased with steeper rate for NOR. Even though the SOR value increased in episodic cases, correlation between temperature and SOR was generally low $\left(R^{2}=0.075\right)$ and even decreased to $0.003 \sim 0.027$ in episodic cases, suggesting that the homogeneous formation of sulfate was not active in the Korean Peninsula, especially in high PM episodic periods. On the other hand, correlation between humidity and SOR increased from 0.03 to 0.38 and 0.11 in Case 1 and Case 2, respectively, implying that heterogeneous sulfate formation reaction was dominant in high PM episodes. As for NOR, correlation with temperature highly increased in high PM episodes in contrast to SOR. However, the correlation with humidity decreased in Case 1 and highly increased in Case 2. For Case 1, it was suggested that $\mathrm{NO}_{2}$ oxidation was mainly caused by homogeneous oxidation. For Case 2, heterogeneous oxidation mainly contributed to forming the nitrate due to the extremely high particle concentration in Asian dust.

The characteristics of chemical components and their ability to change the atmospheric condition during high PM episodes were investigated. Atmospheric conditions such as acidity and oxidation state, determined by chemical characteristics, are reversely affecting the aerosol physical property (aerosol growth), chemical property (chemical reactions), and toxic property. Thus, this study is important to understand basic atmospheric characteristics, physicochemical properties, and their toxicity on public health in the Northeast Asian region.

\section{Conflict of Interests}

The authors declare that there is no conflict of interests regarding the publication of this paper.

\section{Acknowledgments}

This work was supported by the National Institute of Environmental Research and funded by the Korean government (ME).

\section{References}

[1] N. Englert, "Fine particles and human health-a review of epidemiological studies," Toxicology Letters, vol. 149, no. 1-3, pp. 235-242, 2004. 
[2] Inter-Governmental Panel on Climate Change (IPSS), "The climate change 2013-physical science basis," 2013, http://www .climatechange2013.org/images/report/WG1AR5_SPM_FINAL .pdf.

[3] H. Hagino, T. Takada, H. Kunimi, and K. Sakamoto, "Characterization and source presumption of wintertime submicron organic aerosols at Saitama, Japan, using the Aerodyne aerosol mass spectrometer," Atmospheric Environment, vol. 41, no. 39, pp. 8834-8845, 2007.

[4] C. K. Chan and X. Yao, "Air pollution in mega cities in China," Atmospheric Environment, vol. 42, no. 1, pp. 1-42, 2008.

[5] F. Duan, X. Liu, T. Yu, and H. Cachier, "Identification and estimate of biomass burning contribution to the urban aerosol organic carbon concentrations in Beijing," Atmospheric Environment, vol. 38, no. 9, pp. 1275-1282, 2004.

[6] B. Guinot, H. Cachier, J. Sciare, Y. Tong, W. Xin, and Y. Jianhua, "Beijing aerosol: atmospheric interactions and new trends," Journal of Geophysical Research: Atmospheres, vol. 112, no. 14, Article ID D14314, 2007.

[7] J. Sun, Q. Zhang, M. R. Canagaratna et al., "Highly time- and size-resolved characterization of submicron aerosol particles in Beijing using an Aerodyne Aerosol Mass Spectrometer," Atmospheric Environment, vol. 44, no. 1, pp. 131-140, 2010.

[8] A. M. Fiore, D. J. Jacob, I. Bey, R. M. Yantosca, B. D. Field, and A. C. Fusco, "Background ozone over the united states in Summer: origin, trend, and contribution to pollution episodes," Journal of Geophysical Research, vol. 107, article D15, 2002.

[9] P. Pochanart, S. Kato, T. Katsuno, and H. Akimoto, "Eurasian continental background and regionally polluted levels of ozone and CO observed in northeast Asia," Atmospheric Environment, vol. 38, no. 9, pp. 1325-1336, 2004.

[10] H. Tanimoto, Y. Sawa, H. Matsueda et al., "Significant latitudinal gradient in the surface ozone spring maximum over East Asia," Geophysical Research Letters, vol. 32, no. 21, Article ID L21805, 2005.

[11] H. J. Shin, K. M. Cho, J. S. Han, J. S. Kim, and Y. P. Kim, "The effects of precursor emission and background concentration changes on the surface ozone concentration over Korea," Aerosol and Air Quality Research, vol. 12, no. 1, pp. 93-103, 2012.

[12] E. Robinson and R. C. Robbins, "Atmospheric background concentrations of carbon monoxide," Annals of the New York Academy of Sciences, vol. 174, no. 1, pp. 89-95, 1970.

[13] Korea Ministry of Environment (KMOE), Annual Report of Air Quality in Korea 2012, National Institute of Environmental Research, Incheon, South Korea, 2013 (Korean).

[14] Y. S. Ghim, "Impacts of Asian dust on atmospheric environment," Journal of Korean Society for Atmospheric Environment, vol. 27, no. 3, pp. 255-271, 2011 (Korean).

[15] Y. P. Kim and M. J. Yeo, "The trend of the concentrations of the criteria pollutants over Seoul," Journal of Korean Society for Atmospheric Environment, vol. 29, no. 4, pp. 369-377, 2013 (Korean).

[16] J. Kim, C. H. Jung, B.-C. Choi et al., "Number size distribution of atmospheric aerosols during ACE-Asia dust and precipitation events," Atmospheric Environment, vol. 41, no. 23, pp. 4841-4855, 2007.

[17] Korean Statistical Information Service (KOSIS), 2014 (Korean), http://kosis.kr/statisticsList/statisticsList_01List.jsp?Vw cd= MTJTITLE\&parmTabId=M010MT1.

[18] E. H. Kang, J. H. Han, M. H. Lee, G. Lee, and J. C. Kim, "Chemical characteristics of size-resolved aerosols from Asian dust and haze episode in Seoul Metropolitan City," Atmospheric Research, vol. 127, pp. 34-46, 2013.

[19] Metrohm Applikon, MARGA-Monitor for Aerosol and Gases in Ambient Air, Metrohm Applikon, Herisau, Switzerland, 2013.

[20] The National Institute for Occupational Safety and Health (NIOSH), "Elemental carbon (diesel particulate): method 5040," in NIOSH Manual of Analytical Methods, P. M. Eller and M. E. Cassinelli, Eds., National Institute for Occupational Safety and Health, Cincinnati, Ohio, USA, 4th edition, 1996.

[21] B. T. Mader, J. J. Schauer, J. H. Seinfeld et al., "Sampling methods used for the collection of particle-phase organic and elemental carbon during ACE-Asia," Atmospheric Environment, vol. 37, no. 11, pp. 1435-1449, 2003.

[22] Chinese Environmental Monitoring Center, National air quality data, December 2014 (Chinese), http://113.108.142.147:20035/ emcpublish.

[23] K. He, Q. Zhao, Y. Ma et al., "Spatial and seasonal variability of PM 2.5 acidity at two Chinese megacities: insights into the formation of secondary inorganic aerosols," Atmospheric Chemistry and Physics, vol. 12, no. 3, pp. 1377-1395, 2012.

[24] A. Ooki and M. Uematsu, "Chemical interactions between mineral dust particles and acid gases during Asian dust events," Journal of Geophysical Research D: Atmospheres, vol. 110, no. 3, pp. 1-13, 2005.

[25] A. Vlasenko, S. Sjogren, E. Weingartner, K. Stemmler, H. W. Gäggeler, and M. Ammann, "Effect of humidity on nitric acid uptake to mineral dust aerosol particles," Atmospheric Chemistry and Physics, vol. 6, no. 8, pp. 2147-2160, 2006.

[26] H. Yuan, Y. Wang, and G. Zhunag, “The simultaneous determination of organic acid, MSA with the inorganic anions in aerosol and rain water by ion chromatography," Journal of Instrumental Analysis, vol. 22, pp. 11-14, 2003.

[27] R. R. Draxler and G. D. Hess, "An overview of the HYSPLIT4 modelling system for trajectories, dispersion and deposition," Australian Meteorological Magazine, vol. 47, no. 4, pp. 295-308, 1998.

[28] K. Ram, M. M. Sarin, A. K. Sudheer, and R. Rengarajan, "Carbonaceous and secondary inorganic aerosols during wintertime fog and haze over urban sites in the Indo-Gangetic plain," Aerosol and Air Quality Research, vol. 12, no. 3, pp. 355-366, 2012. 

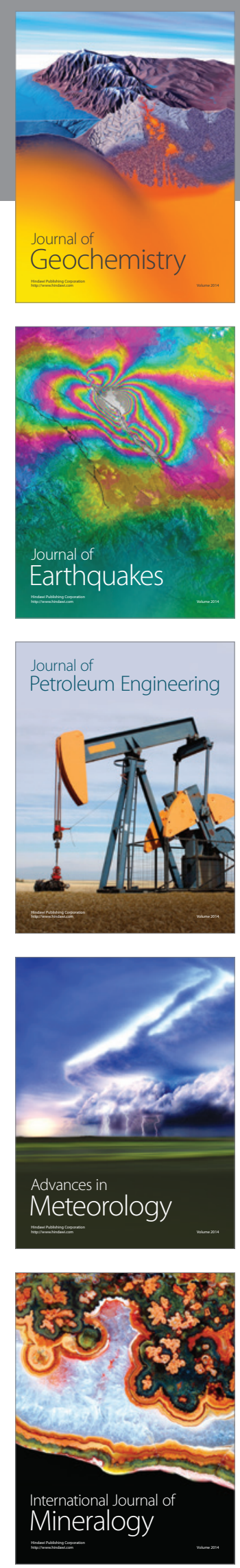
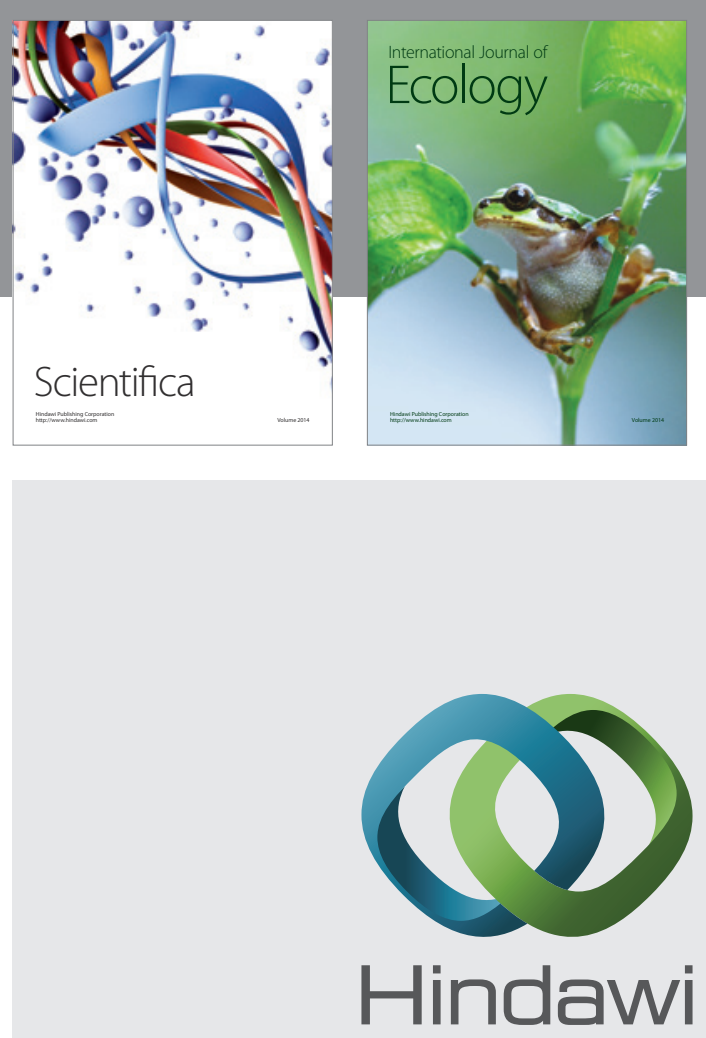

Submit your manuscripts at

http://www.hindawi.com
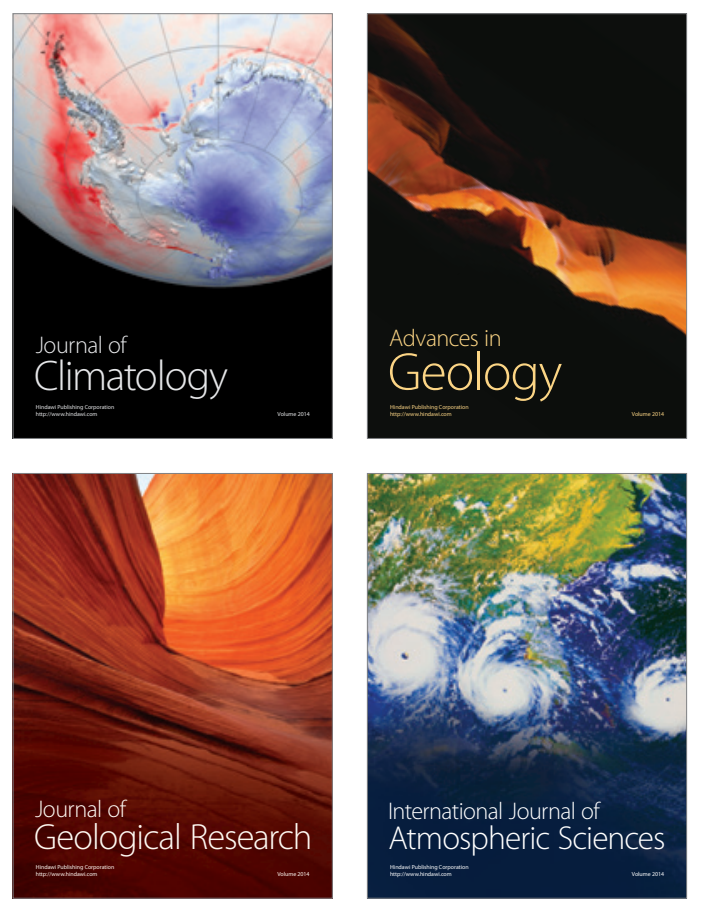

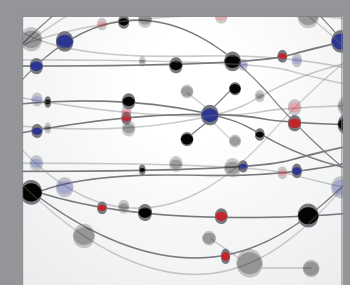

The Scientific

\section{World Journal}
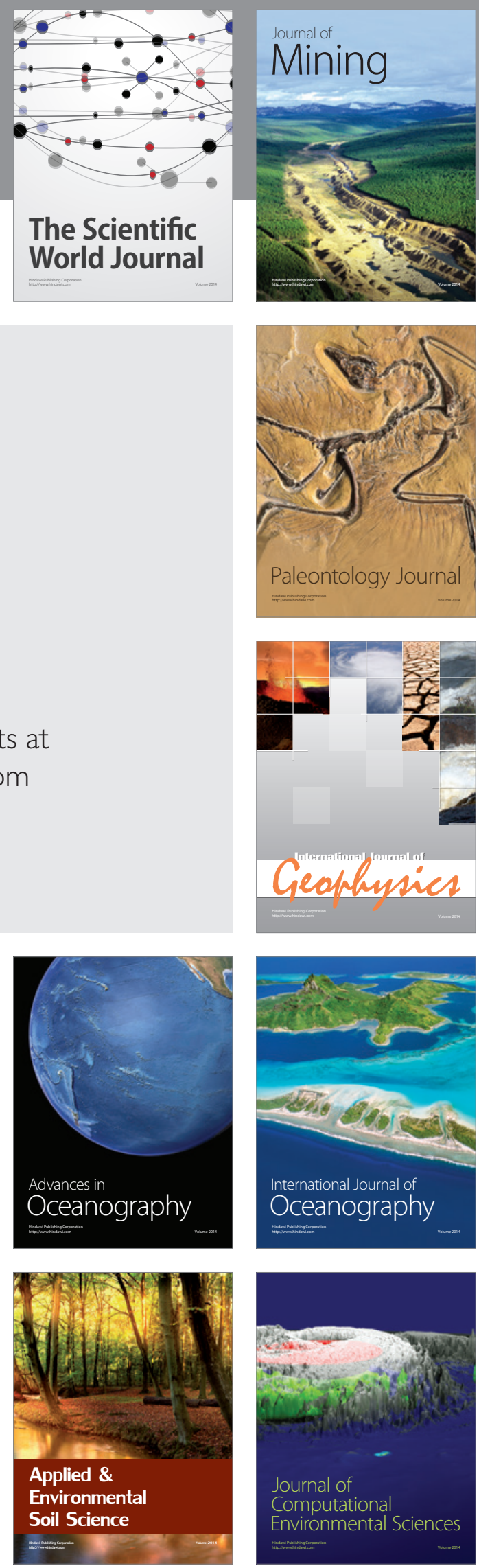